\title{
A Study on Correlations between Computer-Aided Instructions Integrated Environmental Education and Students' Learning Outcome and Environmental Literacy
}

\author{
Colin W. K. Chen ${ }^{1}$, Chenin Chen ${ }^{2 *}$, Chich-Jen Shieh ${ }^{3}$ \\ ${ }^{1}$ International college, Krirk University, Bangkok 10220, THAILAND \\ 2 Chulalongkorn Business School, Chulalongkorn University, Bangkok 10330, THAILAND \\ ${ }^{3}$ Institute of Quantitative Economics, Huaqiao University, Xiamen, Fujian, 361021, CHINA
}

Received 24 February 2020 - Accepted 22 April 2020

\begin{abstract}
Environmental actions without protection desire and skills would be vain. The task of education is to create such thirst and motive under the encouragement of the community. For this reason, it is expected to open students' future green new horizons of environmental awareness with teaching methods and research tools which could enhance students' environmental literacy, when largely promoting the low-carbon and energy-saving sustainable life. In this case, it is necessary to deeply understand students' environmental awareness and teach them with strict curriculum mapping and design to reinforce students' environmental competence so as to cope with currently extreme climate change.

Aiming at students of Tungfang Design University, Taiwan, total 221 students, as the experimental objects, are preceded computer-aided instruction integrated environmental education. The experimental teaching is preceded 3 hours per week for 15 weeks (total 45 hours). The research results show positive relations between 1.environmental education and learning outcome, 2.learning outcome and environmental literacy, and 3.environmental education and environmental literacy. Suggestions are proposed according to the results, expecting to assist domestic students in enhancing self-development through the awareness of the responsibility for environmental issues. Especially, internationally concerned environmental issues would guide the goal of environmental education to social prospective.
\end{abstract}

Keywords: computer-aided instruction, environmental education, learning outcome, environmental literacy, environmental attitude

\section{INTRODUCTION}

In face of current crises, such as climate change, reducing cultivated land caused by land desertification, and pollution of water resource, such ecological crises resulting in economy, food, and even social crises are closely related to the cognition, value, and attitude of humans. Environmental actions without protection desire and skills would be vain. The task of education is to create such thirst and motive under the encouragement of the community. In this case, it is expected to open students' future green new horizons of environmental awareness with teaching methods and research tools which could promote students' environmental literacy, when largely promoting the low-carbon and energy-saving sustainable life. Most domestic students present basic knowledge of environmental education; however, the inadequate environmental awareness results in the lack of the execution of environmental action strategies. As a result, it is necessary to deeply understand students' environmental awareness and teach them with strict curriculum mapping and design to reinforce the environmental competence in order to cope with currently extreme climate change. 


\section{Contribution to the literature}

- Encourage teachers applying computer-aided instruction integrated environmental issues related to the community environment so as to localize global environmental issues and start from oneself.

- Holding environmental education seminars and cultivating seed teachers for rooting and expanding would have environmental education be rooted from schools to families, communities, and society.

- School staff's support of environmental education and consensus of environmental education week, through university assembly, could provide students with opportunities for experience and perception.

Students, on one hand, contact constantly innovative technology and living functions, but, on the other hand, are limited to one-way environmental education knowledge that the environmental education philosophy can hardly be practiced in daily actions in the school teaching situation. Climate change is the education issue which has to be faced. Schools and teachers have to re-position and self-renovate to well prepare for students facing the changing world. Nevertheless, along with the convenience and broadness of information acceptance, students mostly acquire environmental knowledge from mass communication media of "reading newspapers, magazines, books, listening to broadcast, and watching TV", but seldom from "school-arranged keynote speeches or activities". It reveals the shortage of schools offering environmental education channels for students. Students learning liferelated environmental issues could understand sciencerelated concept and knowledge in the issues as well as think and discuss the conflict or dilemmas in the issues. School teachers being able to have students understand the effects of technology development on individuals, society, environment, ecology, or the entire earth through the contents of environmental issues could further have them, from the aspect of humanity concern, adopt actions to protect and cherish ecology. Environmental literacy of a nation relies on good environmental education (Goulgouti et al., 2019; Hunter \& Jordan, 2019). Current environmental education aims to apply environmental issues and the opportunity of field trips to cope with the rapidly changing era (Arioder et al., 2020). Teachers and students should constantly learn and promote the ideas and thoughts in the new time. Once students could comprehend the content of the cultivated environmental education and be aware of the importance, they would promote the awareness of and sensitivity to environmental issues as well as the respect and inspiration of environmental ethics to further enhance the ability to face and deal with surrounding environmental issues, increase the twoway interaction with the environment, and promote the environmental literacy through actual life experience and learning. Consequently, computer-aided instruction integrated environmental education is applied in this study to discuss students' environmental literacy and learning outcome. It is expected to help domestic students enhance self-development through individual responsibility for and awareness of environmental issues, especially internationally concerned environmental issues, to guide the goal of environmental education to social perspectives.

\section{LITERATURE REVIEW}

Chen (2017) indicated that computer-aided instruction, in much research, was proven the effectiveness on the promotion of students' academic achievement. Computer-aided instruction was a practicable teaching method as it could promote students' academic achievement and enhance the learning interests and attitude. Moreover, computeraided instruction could reduce students' time for learning. Fan and Ma (2018) mentioned that computeraided instruction utilized the characteristics of computers (texts, pictures, and images) and was the teaching software learning system constructed by adjusting task complexity and learning speed according to learners' individual differences. Chalmers et al. (2018) explained computer-aided instruction as the interactive teaching using computers for directly helping learners' learning. Computers were used for providing course contents and preceding teaching through practice, tutorial, and simulation to achieve the teaching objectives. However, the word computer in computeraided instruction was a general name, referring to teaching activity with computers as the control. For this reason, instructional multimedia and intelligent tutoring systems were covered in computer-aided instruction. Ene and Upton (2018) pointed out "computer-aided instruction" as an interactive teaching method using computer systems for directly helping students' learning, utilizing the characteristics of computer systems for providing teaching situations, presenting course contents, controlling teaching progress according to students' levels, and preceding teaching with tutors, training and practice, tutorial, problem-solving, games, and simulation to achieve instructional objectives.

Hui et al. (2018) considered that environmental education activity could effectively enhance students' learning outcome on environmental awareness and sensitivity, environmental concept knowledge, environmental value and attitude, environmental action skills, and environmental action experiences. Cheeseman and Wright (2019) pointed out the significantly positive correlation between environmental education and environmental learning outcome, i.e. 
remarkable effects of environmental education knowledge on environmental learning outcome. Boca and Saraçlı (2019) found out notable correlations between environmental learning outcome and environmental education, but not significant relations with other variables. Moseley et al. (2019) discovered that environmental education knowledge and skills are the major factors in environmental learning outcome, and action intention was the key factor in teachers' environmental teaching behaviors. In the discussion of elementary pupils' environmental learning outcome, Samuelsson et al. (2019) found out remarkable correlations between environmental education knowledge and learning outcome; the group with high environmental knowledge outperformed the group with low environmental knowledge on "overall environmental behavior", "ecological management", and "consumption action" in learning outcome. From above literatures, the following hypothesis is inferred.

H1: Environmental education presents positive relations with learning outcome.

Woosnam et al. (2018) stated that environmental education would cultivate humans' environmental knowledge and sensitivity that the learning outcome, through the interaction and concern with the environment, aimed to cultivate environmental attitude and value to further enhance humans' emphasis on the nature and ecological environment. Moreover, the knowledge and concept of international environmental issues would reinforce humans' responsibility for the environment and the action to the sustainable environmental survival. Flanagan et al. (2019) indicated that the objectives and teaching methods of environmental education could develop the function of environmental education to achieve the learning outcome, inspire humans' environmental awareness and environmental sensitivity, enrich the environmental concept, implement the environmental actions, and cultivate the environmental ethics value to promote environmental literacy and solve currently encountered environmental threats. Campana et al. (2019) stated that environmental education learning outcome could effectively enhance students' environmental awareness and sensitivity, environmental concept knowledge, environmental value and attitude, environmental action skills, and environmental action experiences of students' environmental literacy. Meloni et al. (2019) considered that environmental education learning outcome aimed to cultivate citizens presenting environmental literacy and taking responsible environmental behavior. From above literatures, the following hypothesis is inferred.

H2: Learning outcome shows positive relations with environmental literacy.

Jiang et al. (2017) mentioned that environmental education, depending on the responsible environmental awareness, cultivated positive environmental attitude and active participation in environmental actions to enhance environmental literacy through the knowledge of natural ecological conservation and environmental justice. Hosany et al. (2017) considered that environmental education aimed to cultivate citizens' environmental literacy and responsible environmental behavior. The promotion of environmental literacy should be established on the understanding of ecology, the evaluation of environment, and responsible behaviors. Students would really evaluate environmental ecology and take responsible behaviors after understanding the value and importance of ecology. Alonso-Vazquez et al. (2019) mentioned that the promotion of environmental literacy should be established on the understanding of ecology, the evaluation of environment, and responsible behaviors. Students would appear ecological evaluation and responsible behaviors after understanding the value and importance of ecology. Dynia et al. (2018) stated that environmental education cultivated positive environmental attitude, according to responsible environmental awareness, and enhance environmental literacy by active participation in environmental actions, knowledge of natural ecological conservation, and environmental justice. Rahman \& Nasri (2018) considered that cultivating citizens with environmental literacy through education could protect the citizens and improve the environmental ethics, knowledge, attitude, skills, and value. In this case, environmental education did not simply instruct related knowledge, but covered value clarification, attitude establishment, and the learning to improve environmental skills. Accordingly, the following hypothesis is inferred.

H3: Environmental education reveals positive relations with environmental literacy.

\section{SAMPLE AND INDICATOR}

\section{Operational Definition}

\section{Environmental education}

The dimensions of environmental education proposed by Jo et al. (2018) are used for deep discussion of environmental education in this study.

1. Knowledge concept: referring to the environment and the natural ecology, geographic characteristics, environmental ecological cycle, pollution concept, environmental preservation, and limited environmental resources of surrounding environment.

2. Affective concept: referring to the integration of environmental concern, appreciation of the beauty of natural ecology, correct environmental ethics and value, and environmental humanities and arts.

3. Technological concept: referring to the behavior of environmental pollution control, water purification, 
environmental resource development and management, environmental resource conservation, and environmental maintenance.

\section{Learning outcome}

Referring to $\mathrm{Lu}$ et al. (2017), three dimensions of environmental knowledge, environmental skills, and environmental attitude are covered for environmental education learning outcome.

1. Environmental knowledge: To assist social groups and individuals in acquiring various experiences in and basic understanding about environment and the problems.

2. Environmental skills: To provide social groups and individuals with skills to identify and solve environmental issues.

3. Environmental attitude: To assist social groups and individuals in acquiring the value to concern about the environment and promising to actively participate in environmental improvement and protection.

\section{Environmental literacy}

Referring to Fu et al. (2017), environmental literacy contains the following dimensions in this study.

1. Environmental sensitivity: Awareness of distinct environmental disruption and pollution as well as the appreciation of the beauty of environment and sensitivity to natural environment and artificial environment.

2. Action experience: Environmental behaviors taken in daily life and the actual participation in relevant environmental activity.

\section{Research Sample and Object}

Aiming at students of Tungfang Design University, Taiwan, total 221 students, as the experimental objects, are preceded computer-aided instruction integrated environmental education in this study. The experimental teaching is preceded 3 hours per week for 15 weeks (total 45 hours). Tungfang Design University, as the first design university in Taiwan, is a design-centered university of technology, containing three colleges of art and design, consumer living designing, and applied design. The students are therefore selected for this study.

\section{Reliability and Validity Test}

Validity refers to a measurement tool being able to really measure what a research intends to measure. Validity is generally divided into content validity, criterion-related validity, and construct validity. The questionnaire items in this study are referred to domestic and international researchers' research items that the questionnaire presents certain content validity. The dimensions of environmental education, learning outcome, and environmental literacy are tested the overall structural causality with linear structural relations model, and the data input are based on the correlation coefficient matrix of above observed variables. The linear structural relations model analysis results show the overall model fit reaching the reasonable range that it presents favorable convergent validity and predictive validity. Item-to-total correlation coefficients are used in this study for testing the construct validity of the questionnaire content, i.e. reliability analysis, and the calculated item-to-total correlation coefficients are applied to judge the questionnaire content. The item-to-total correlation coefficients of the dimensions are higher than 0.7, revealing certain construct validity of the dimensions.

To further understand the reliability and validity of the questionnaire, reliability and validity are further analyzed. The higher Cronbach's a shows the better reliability. The formal questionnaire is developed accordingly to the standard, and the Cronbach's a appears in $0.70 \sim 0.90$, apparently conforming to the reliability range.

\section{EMPIRICAL RESULT ANALYSIS}

\section{LISREL Model Indicator}

LISREL (linear structural relation) model combines factor analysis and path analysis in traditional statistics and adds simultaneous equations in econometrics to simultaneously calculate multiple factors and multiple casual paths. The model fit could be evaluated from preliminary fit criteria, overall model fit, and fit of internal structure of model.

The research data are organized in Table 1 . The preliminary fit, internal fit, and overall fit of the model are explained as below.

The model analysis results, Table 1 , reveal that three dimensions of environmental education (knowledge concept, affective concept, technological concept) could remarkably explain environmental education ( $t>1.96$, $\mathrm{p}<0.05)$, three dimensions of learning outcome (environmental knowledge, environmental skills, environmental attitude) could notably explain learning outcome $(t>1.96, p<0.05)$, and two dimensions of environmental literacy (environmental sensitivity, action experience) could significantly explain environmental literacy $(\mathrm{t}>1.96, \mathrm{p}<0.05)$. Apparently, the overall model in this study presents good preliminary fit.

In terms of internal fit, environmental education shows positive and remarkable correlations with learning outcome $(0.816, \mathrm{p}<0.01)$, learning outcome reveals positive and notable correlations with environmental literacy $(0.864, \mathrm{p}<0.01)$, and environmental education appears positive and 
Table 1. Overall linear structural model analysis result

\begin{tabular}{|c|c|c|c|c|}
\hline Evaluation item & Parameter/evaluation star & dard & Result & $\mathrm{t}$ \\
\hline \multirow{8}{*}{ preliminary fit } & \multirow{3}{*}{ environmental education } & knowledge concept & 0.704 & $10.36^{* *}$ \\
\hline & & affective concept & 0.683 & $8.43^{*}$ \\
\hline & & technological concept & 0.675 & $7.66^{*}$ \\
\hline & \multirow{3}{*}{ learning outcome } & environmental knowledge & 0.716 & $11.48^{* *}$ \\
\hline & & environmental skills & 0.724 & $12.57^{* *}$ \\
\hline & & environmental attitude & 0.697 & $9.58^{*}$ \\
\hline & \multirow{2}{*}{ environmental literacy } & environmental sensitivity & 0.735 & $14.63^{* *}$ \\
\hline & & action experience & 0.742 & $15.11^{* *}$ \\
\hline \multirow{3}{*}{ internal fit } & \multicolumn{2}{|c|}{ environmental education $\rightarrow$ learning outcome } & 0.816 & $23.69^{* *}$ \\
\hline & \multirow{2}{*}{\multicolumn{2}{|c|}{$\begin{array}{l}\text { learning outcome } \rightarrow \text { environmental literacy } \\
\text { environmental education } \rightarrow \text { environmental literacy }\end{array}$}} & 0.864 & $37.28^{* *}$ \\
\hline & & & 0.847 & $30.44^{* *}$ \\
\hline \multirow{4}{*}{ overall fit } & \multicolumn{2}{|l|}{$\mathrm{X} 2 / \mathrm{Df}$} & \multicolumn{2}{|c|}{1.682} \\
\hline & \multicolumn{2}{|l|}{ GFI } & \multicolumn{2}{|c|}{0.977} \\
\hline & \multicolumn{2}{|l|}{ AGFI } & \multicolumn{2}{|c|}{0.945} \\
\hline & \multicolumn{2}{|l|}{ RMR } & \multicolumn{2}{|c|}{0.005} \\
\hline
\end{tabular}

Note: * stands for $\mathrm{p}<0.05,{ }^{* *}$ for $\mathrm{p}<0.01,{ }^{* * *}$ for $\mathrm{p}<0.001$

Table 2. Hypothesis test

\begin{tabular}{lcccc}
\hline Research hypothesis & Correlation & Empirical result & $\mathrm{P}$ & Result \\
\hline H 1 & + & 0.816 & $\mathrm{P}<0.01$ & supported \\
H 2 & + & 0.864 & $\mathrm{P}<0.01$ & supported \\
H 3 & + & 0.847 & $\mathrm{P}<0.01$ & supported \\
\hline
\end{tabular}

significant correlations with environmental literacy (0.847, p <0.01), showing that H1, H2, and H3 are supported.

In regard to overall model fit, the overall model fit standards $\chi 2 / D f=1.682$, smaller than the standard 3, and $\mathrm{RMR}=0.005$ reveal the proper results of $\chi 2 / \mathrm{DF}$ and $\mathrm{RMR}$. Furthermore, chi-square is sensitive to sample size that it is not suitable for directly judging the fit. However, the overall model fit standards GFI=0.977 and AGFI=0.945 are higher than the standard 0.9 (the closer GFI and AGFI to 1 revealing the better model fit) that this model presents favorable fit indices.

\section{CONCLUSION}

The research results reveal that students, after the computer-aided instruction integrated environmental education, could acquire distinct lively teaching on the Internet and appear deep impression and affection to the nature to achieve the learning effect. From the environment and species in students' daily life, the students are instructed environmental knowledge and cultivated the love to the environment. The computeraided instruction integrated environmental education extends the concern about environmental issues to deeply understand the environmental ecology and environmental disruption issues in the hometowns. Under the negative crisis awareness and the positive home love, students unconsciously appear the idea of environmental protection; that is environmental literacy. Computer-aided instruction integrated environmental education allows students correctly comprehending the dependency between behavior and environment. When students realize the effect of human behaviors on environmental disruption, they would gradually weaken the egocentric attitude, start to calmly consider the ethics of people and environment, and consider the equality of humans and other creatures. What is more, students do not know the correlation between the daily behavior and the surrounding animals and plants that they would not practice environmental protection, even though they enjoy the nature. The computer-aided instruction integrated environmental education horizontally links two independent ideas in students' cognition through the characteristics of computers (text, pictures, and images) to have students be willing to combine the knowledge and actions to promote the environmental literacy fundamentally.

\section{SUGGESTION}

From the research results and findings, the following practical suggestions are proposed in this study.

1. The significant effect of computer-aided instruction integrated environmental education on students' learning outcome and environmental literacy is discovered in this study. It is suggested that local and national environmental education could be integrated into materials, like native teaching materials, with computer-aided instruction. Schools could integrate computer-aided instruction integrated environmental education into the teaching of flexible curriculum, integrated curriculum, nature and science, or life education and civil and social curriculum in high schools as well as encourage teachers applying computer-aided instruction integrated environmental issues related to the community environment so as to localize global 
environmental issues and start from oneself, i.e. the awareness of global environmental issues being solved locally.

2. Current environmental issues are mostly promoted and handled by environmental units. The youth should be cultivated the willingness and intelligence to grasp problems, provided tools for collecting and analyzing data, assisted in exploring the value and cultural thoughts in the growth process, and provided first-hand experience and opportunities for full participation. These are absolutely necessary for humans' environmental protection and improvement. For this reason, holding environmental education seminars and cultivating seed teachers for rooting and expanding would have environmental education be rooted from schools to families, communities, and society.

3. Schools could plan environmental education being school-oriented courses to reinforce students' environmental knowledge, attitude, and behavior through relevant activities and courses as well as integrate into local nature, ecology, and social environment. In addition to garbage separation and reduction in schools, school staff's support of environmental education and consensus of environmental education week, through university assembly, could provide students with opportunities for experience and perception.

\section{REFERENCES}

Alonso-Vazquez, M., Packer, J., Fairley, S., \& Hughes, K. (2019). The role of place attachment and festival attachment in influencing attendees' environmentally responsible behaviours at music festivals. Tourism Recreation Research, 44(1), 91-102. https:/ / doi.org/10.1080/02508281.2018.1545393

Arioder, L. J. Q., Arioder, V. Q., Quintana, V. V., \& Dagamac, N. H. (2020). Application of Constructivist Teaching Approach in Introducing New Environmental Concepts to Young Elementary Students in the Philippines: A Small Class Sized Experience from Slime Moulds Modeling. Interdisciplinary Journal of Environmental and Science Education, 16(2), e2214. https:/ / doi.org/10.29333/ijese/7818

Boca, G. D., \& Saraçlı, S. (2019). Environmental Education and Student's Perception, for Sustainability. Sustainability, 11(6), 1553. https://doi.org/10.3390/su11061553

Campana, K., Kociubuk, J., \& Mills, J. E. (2019). Making Space for Storytime: The Role of the Environment in the Production of Storytime. Public Library Quarterly, 1-17. https:/ / doi.org/10.1080/01616846. 2019.1622396
Chalmers, C., Mowat, E., \& Chapman, M. (2018). Marking and providing feedback face-to-face: Staff and student perspectives. Active Learning in Higher Education, 19(1), 35-45. https://doi.org/10.1177/ 1469787417721363

Cheeseman, A., \& Wright, T. (2019). Examining environmental learning experiences at an earth education summer camp. Environmental Education Research, 1-13. https://doi.org/10.1080/13504622. 2018.1509301

Chen, K. T. (2017). An exploratory study of NNES graduate students' reading comprehension of English journal articles. Reading in a Foreign Language, 29(1), 20-35.

Dynia, J. M., Schachter, R. E., Piasta, S. B., Justice, L. M., O'Connell, A. A., \& Yeager Pelatti, C. (2018). An empirical investigation of the dimensionality of the physical literacy environment in early childhood classrooms. Journal of Early Childhood Literacy, 18(2), 239-263. https://doi.org/10.1177/1468798416652 448

Ene, E., \& Upton, T. A. (2018). Synchronous and asynchronous teacher electronic feedback and learner uptake in ESL composition. Journal of Second Language Writing, 41, 1-13. https:/ / doi.org/10.1016 /j.jslw.2018.05.005

Fan, N., \& Ma, Y. (2018). The Role of Written Corrective Feedback in Second Language Writing Practice. Theory and Practice in Language Studies, 8(12), 1629. 1635. https:/ / doi.org/10.17507/tpls.0812.08

Flanagan, C. A., Gallay, E., Pykett, A. A., \& Smallwood, M. (2019). The Environmental Commons in Urban Communities: The Potential of Place-Based Education. Frontiers in psychology, 10, 226. https:/ / doi.org/10.3389/fpsyg.2019.00226

Fu, L., Zhang, Y., Xiong, X., \& Bai, Y. (2017). ProEnvironmental Awareness and Behaviors on Campus: Evidence from Tianjin, China. Eurasia Journal of Mathematics, Science and Technology Education, 14(1), 427-445. https:/ / doi.org/10.12973 / ejmste/77953

Goulgouti, A., Plakitsi, A., \& Stylos, G. (2019). Environmental Literacy: Evaluating Knowledge, Affect, and Behavior of Pre-service Teachers in Greece. Interdisciplinary Journal of Environmental and Science Education, 15(1), e02202. https://doi.org/ 10.29333 /ijese/ 6287

Hui, N., Saxe, S., Roorda, M., Hess, P., \& Miller, E. J. (2018). Measuring the completeness of complete streets. Transport reviews, 38(1), 73-95. https:/ / doi.org/10.1080/01441647.2017.1299815

Hunter, R. H., \& Jordan, R. C. (2019). The TELA: A New Tool for Assessing Educator Environmental Literacy. Interdisciplinary Journal of Environmental 
and Science Education, 15(1), e02201. https:/ / doi.org/10.29333/ijese/6286

Jiang, Y., Ramkissoon, H., Mavondo, F. T., \& Feng, S. (2017). Authenticity: The link between destination image and place attachment. Journal of Hospitality Marketing $\mathcal{E} \quad$ Management, 26(2), 105-124. https:// doi.org/10.1080/19368623.2016.1185988

Jo, Y.-I., Lee, J.-L., \& Koo, J.-H. (2018). Effect of Physical Environment and Programs on the Social Interaction of Youth Space Users in Seoul in the Case of Pilot Projects. Sustainability, 10(12), 4515. https:/ / doi.org/10.3390/su10124515

Lu, H., Liu, X., Chen, H., Long, R., \& Yue, T. (2017). Who contributed to "corporation green" in China? A view of public-and private-sphere proenvironmental behavior among employees. Resources, Conservation and Recycling, 120, 166-175. https: / / doi.org/10.1016/j.resconrec.2016.12.008

Meloni, A., Fornara, F., \& Carrus, G. (2019). Predicting pro-environmental behaviors in the urban context: the direct or moderated effect of urban stress, city identity, and worldviews. Cities, 88, 83-90. https:// doi.org/10.1016/j.cities.2019.01.001

Moseley, C., Summerford, H., Paschke, M., Parks, C., \& Utley, J. (2019). Road to collaboration: Experiential learning theory as a framework for environmental education program development. Applied Environmental Education \& Communication, 1-21. https:/ / doi.org/10.1080/1533015X.2019.1582375

Rahman, N. A., \& Nasri, N. M. (2018). Environmental Literacy: Indigenizing Environmental Education. Creative Education, 9(14), 2148-2160. https:/ / doi.org /10.4236/ce.2018.914156

Samuelsson, K., Colding, J., \& Barthel, S. (2019). Urban resilience at eye level: Spatial analysis of empirically defined experiential landscapes. Landscape and Urban Planning, 187, 70-80. https:/ / doi.org/10.1016/j.landurbplan.2019.03.015

Woosnam, K. M., Aleshinloye, K. D., Ribeiro, M. A., Stylidis, D., Jiang, J., \& Erul, E. (2018). Social determinants of place attachment at a World Heritage Site. Tourism management, 67, 139-146. https:/ / doi.org/10.1016/j.tourman.2018.01.012

\section{http://www.ejmste.com}

